

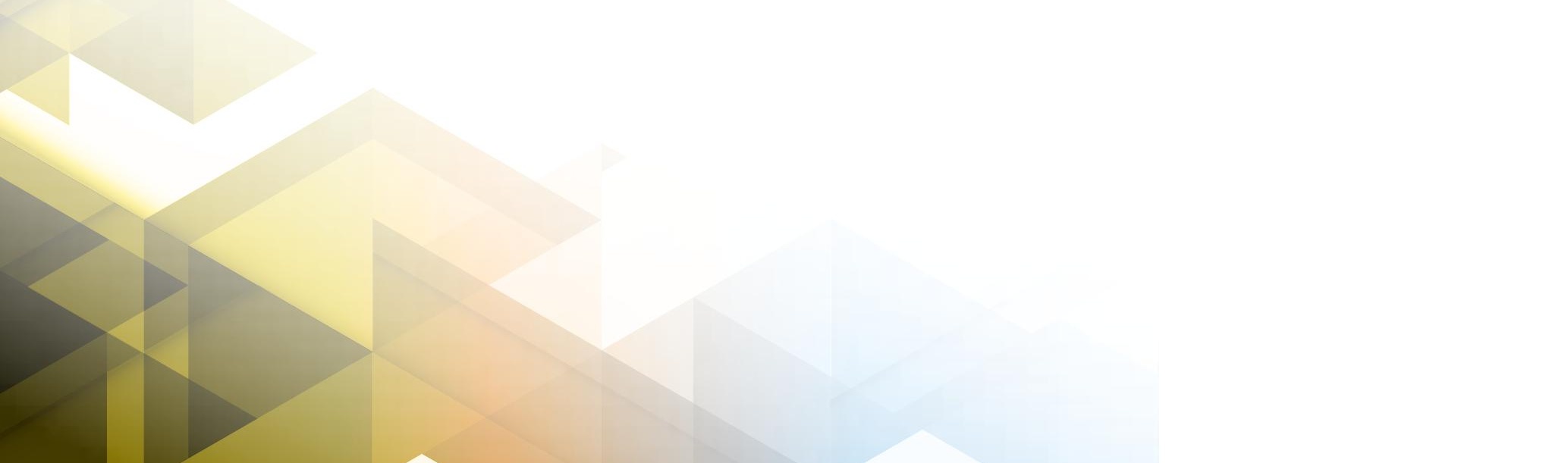




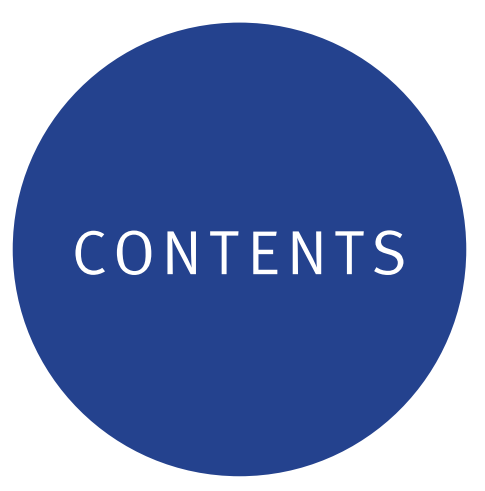

Executive Summary

1. Mental health literacy defined

2. A critique of current mental health literacy

2.1 Experience turned into illness

2.2 Encouraging the prescribing of medication instead of non-pharmaceutical measures

2.3 Language that harms

2.4 An inherently stigmatising narrative 9

2.5 De-contextualising human experience 9

2.6 Discouraging community partnership in preventative mental health _._. 10

2.7 Messaging that assumes available and appropriate clinical pathways and service provision

2.8 Problematic for suicide prevention _- 11

2.9 Lacks gender differentiation and specificity

2.10 Overwhelms the mental health system with demand 12

3. A situational approach to mental health literacy 14

3.1 Defining the situational approach

3.2 Normalising human distress _. 16

3.3 Contextualising human distress ___ 17

3.4 Promoting language \& definitions in mental health
that preserve people's dignity

3.5 Community capacity building education for preventative mental health and suicide prevention

3.6 Gender differentiation and specificity 22

3.7 De-mystifying high intensity mental health difficulties _._. 22

3.8 Workforce education and continuing professional development (CPD) _ 22

3.9 Emphasis on promotion, prevention, and early intervention for mental health, and primary and secondary prevention in suicide prevention 23

3.10 Lobbying government, corporate industry, and community leaders _._._. 23

3.11 Supporting change in primary care and broadening referral options _____ 23 


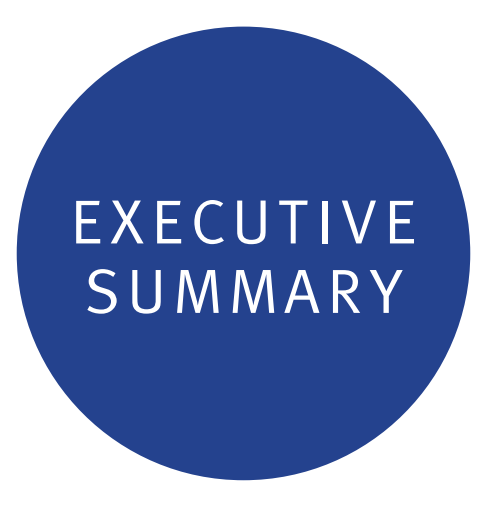

Initiatives of mental health literacy in Australia have met with significant support from employers, schools, and the public. There has been much goodwill surrounding efforts to improve levels of understanding of mental health difficulties, and how to provide appropriate support to people needing assistance with them. Nonetheless, if future mental health literacy initiatives are to remain deserving of the confidence and support of the general community, and of public and private sector funding, we need to ensure that their content has integrity, is appropriate, and can achieve significant positive outcomes.

It is now quite common to hear the terms: 'mental illness', 'mental disorder', and 'mental health', and most people are now aware that there is a considerable repertoire of psycho-active drug treatments applied to 'mental illness'. Most people also know of someone that is receiving drug treatment or psychological treatment for depression, anxiety, or some other mental health difficulty.

Communities have been saturated with mass media and printed materials conveying various aspects of this mental illness and treatment narrative, which has largely been taken for granted as authoritative because it uses medical language and is interlinked with medical practice. Most consultations focusing on people's 'mental health' occur first in general medical practice. ${ }^{1}$

Current mental health literacy messaging and initiatives are largely in continuity with this medical framework, its use of psycho-pathological categories, and its approach to treating 'mental illness'.

A situational approach to mental health literacy represents a significant departure from the current medical framework and its emphasis on illness and the use of illness language relating to mental health. It reconceptualises a broad spectrum of human distress, as non-illness, and remediable largely with nonmedical intervention. In so doing, it also opens up a whole new potential for meaningful community engagement in the endeavour of psychological support, preventative mental health, and suicide prevention. This approach may potentially remove a significant burden of service demand and cost from our overwhelmed mental health system - particularly services that currently deal with high prevalence mental health difficulties, and may provide much more humane and satisfactory outcomes for consumers.

The first part of the following discussion consists of a detailed critique of the content of current mental health literacy, mainly focusing on its core components. Though mental health literacy takes a variety of different forms, these core components appear to remain more or less constant. In the second part of the discussion, the alternative, and almost comprehensively different situational approach to mental health literacy is presented. This may not be popular with institutions that are heavily invested in training curricula and programs promoting the current approach to mental health literacy. Nor will it necessarily sit comfortably with some service providers wed to the core narrative and practices of the existing mental health system. Nevertheless, with so much at stake socially, economically, and ethically, it is imperative that this subject be honestly considered and its implications dispassionately appraised. 


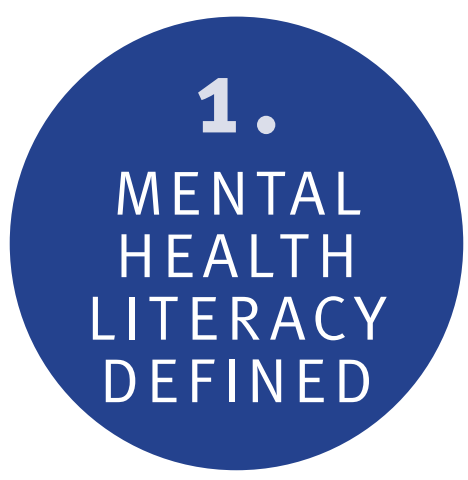

\section{Mental health literacy defined}

Mental health literacy generally consists of several major components: recognition (symptom or illness recognition), knowledge (about sources of information, risk factors, causes, self-help and professional help), and attitudes (about mental illness, sufferers, and help-seeking). 2,3,4

The concept of mental health literacy is derivative of physical health literacy, the purpose of which is to increase patient knowledge about physical health, illnesses, and treatments. ${ }^{5}$

\section{THREE MAIN COMPONENTS OF CURRENT MENTAL HEALTH LITERACY}

\begin{tabular}{ll} 
Recognition & Identification of illness and illness symptoms \\
\hline Knowledge & $\begin{array}{l}\text { Understanding causes, risk factors, options for self-treatment and } \\
\text { professional treatment, and sources of information about mental } \\
\text { illness }\end{array}$
\end{tabular}

Attitudes

About mental illness, sufferers, and help-seeking

Mental health literacy in Australia has been promoted in several major ways: through whole of community campaigns (mainly focussing on depression), school based mental illness education and interventions, and individual training programs, such as mental health first aid (and adaptations of it) which has found its way into industry and broadly across communities and human service organisations. ${ }^{6,7,8}$

2. Jorm, A.F., Korten, A.E., Jacomb, P.A., Christensen, H., Rodgers, B. \& Pollitt, P. (1997). Mental health literacy: a survey of the public's ability to recognise mental disorders and their beliefs about the effectiveness of treatment. Medical Journal of Australia, 166, 182-186

3. Jorm, Anthony F. (2000). Mental health literacy: public knowledge and beliefs about mental disorders PDF. British Journal of Psychiatry.

4. O'Connor, Matt; Casey, Leanne; Clough, Bonnie (2014-08-01). Measuring mental health literacy - a review of scale-based measures. Journal of Mental Health. 23 (4): 197-204. doi:10.3109/09638237.2014.910646. ISSN 0963-8237.

5. Institute of Medicine (U.S.)., Hewitt, M., \& Maria Hewitt. (2012). Facilitating state health exchange communication through the use of health literate practices: workshop summary (Health Literate Practices) (1st ed.). National Academies Press.

6. Jorm, A.F., Christensen, H. \& Griffiths, K.M. (2005). The impact of beyondblue: the national depression initiative on the Australian public's recognition of depression and beliefs about treatments. Australian and New Zealand Journal of Psychiatry, 39, 248-254

7. MindMatters Evaluation Consortium (2000). Report of the mindmatters (National Mental Health in Schools Project) Evaluation Project, vols 1-4. Newcastle: Hunter Institute of Mental Health.

8. Kitchener, B.A. \& Jorm, A.F. (2006). Mental Health First Aid training: review of evaluation studies. Australian and New Zealand Journal of Psychiatry, 40, 6-8. 


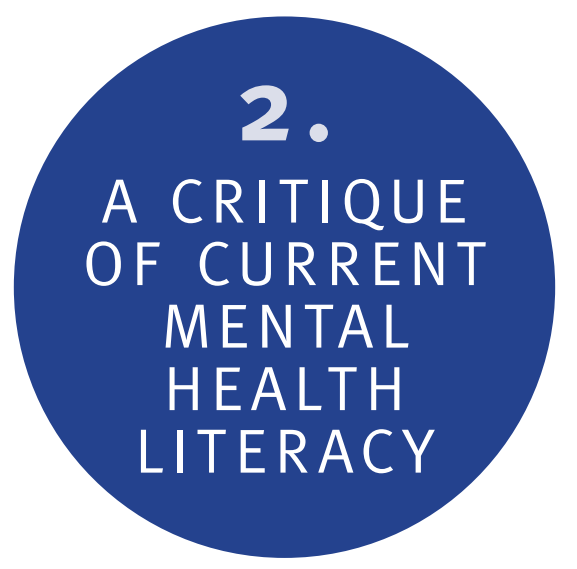

From the outset, it is important to recognise that current initiatives of mental health literacy are largely well-intentioned, and mirror similar efforts in other Western countries. Nonetheless, it is needful to critique this framework before outlining the contrasting merits of a shift to a situational approach to mental health literacy.

\subsection{Experience turned into illness}

The mental illness narrative that characterises our current mental health system, and which is articulated through mental health literacy and suicide prevention initiatives, is grounded in the classical medical paradigm of detecting, diagnosing, and treating disease. ${ }^{9}$ Though helpful in responding to physical ailments, this paradigm falters considerably in its application to distressing human experience, which is not only uniquely individual but can only to some degree be made sense of, as it is mediated through language, and interpreted by inference. ${ }^{10}$

Human experience is the product of a complex interplay of mind, emotions, behaviour, physical sensations, and factors of social and physical environments. To 'shoehorn' this dynamic experience into static psychopathological illness categories, is arguably both a departure from science and from good clinical practice; it is a form of reductionism reflected in the saying: if all one has is a hammer, all one sees is nails.

Allowing the mental illness narrative to engulf, medicalise, and redefine as pathological, much common (albeit sometimes very difficult and debilitating) human experience, can be seen in the example of depression, which in no small way has been popularised by mental health literacy campaigning.

The status of depression in our society is arguably not only exaggerated and misleading, but also significantly harmful and economically costly. Once an obscure psychiatric diagnosis (originally termed melancholia), depression is now deemed to be an 'epidemic' and a 'serious social issue'. Major or intense depression can be profoundly challenging. The problem is, depression is now a diagnostic explanation applied to a broad range of human distress that does not warrant an illness diagnosis or medication in most cases, even though it might be sufficiently intense to warrant referral for counselling or psychological support. Nevertheless, 'depression' has been popularised in such a way as to dominate contemporary thinking about the experience of distress, unhappiness, and dissatisfaction. ${ }^{11}$

\subsection{Encouraging the prescribing of medication instead of non-pharmaceutical measures}

Relating to the example of depression, which is now diagnosed with greater frequency than throughout most of the twentieth century: its 'prevalence' has attracted an enormous cost associated with its

9. Pan, W., \& Zhou, H. (2013). Integrative Medicine: A Paradigm Shift in Clinical Practice. International Journal Of Integrative Medicine, 1. http://dx.doi.org/10.5772/56817

10. Ashfield, J., Macdonald, J., \& Smith, A. (2017). A 'situational approach' to suicide prevention: why we need a paradigm shift for effective suicide prevention. Adelaide: Australian Institute of Male Health and Studies \& Western Sydney University. Retrieved from http:// malesuicidepreventionaustralia.com.au/papers/

11. Raven, M. (2012). Depression and antidepressants in Australia and beyond: a critical public health analysis. (Doctoral thesis) (pp. 13-14) University of Wollongong, Faculty of Arts. 
'cure', being the main condition for which anti-depressant medication is prescribed. ${ }^{12,13}$ In Australia, antidepressant utilisation nearly trebled between 1990 and 1998, and has continued to increase. ${ }^{14,15,16}$ It is interesting to note that, of OECD nations, Australia is currently the second-highest prescriber of antidepressant drugs. ${ }^{17}$

Vastly more people are now being diagnosed with depression, and prescribed antidepressants, than several decades ago. These developments have profound social, economic, and public health implications. Prevalence estimates of depression have been found to be exaggerated and flawed. Clinical assessments based on problematic diagnostic criteria, and powerful marketing biases favouring biological explanations of depression (such as those emphasising the role of serotonin) have aggressively popularised the use of drugs as a solution to depression, the efficacy of which is overstated, and the safety and adverse effects understated. ${ }^{11}$

Just as problematic is the degree to which anti-depressants and other psycho-active drugs are often prescribed alone, offering less chance of recovery, because patients don't understand (nor are necessarily informed) that such medications may only afford symptomatic relief, when in fact addressing issues or influences strongly associated with their condition might be far more beneficial. An emphasis on illness and drug treatment can too easily side-line lifestyle changes and other self-help measures which may be more beneficial in combination, or may, individually in some cases, have comparable or greater efficacy than drug treatments, such as light exposure therapy, structured daily physical activity, reduced alcohol consumption, a balanced diet, and measures to improve sleep. ${ }^{18,19,20,21,22,23,24,25,26}$ Too often, even when such measures are recommended to patients they are not a first line approach but an adjunct to medication, and are thus perceived as recommended but non-essential alongside the more medically definitive drug prescription.

11. Raven, M. (2012). Depression and antidepressants in Australia and beyond: a critical public health analysis. (Doctoral thesis) (pp. 13- 14) University of Wollongong, Faculty of Arts.

12. Norman, Trevor R. (May 2006). Prospects for the treatment of depression. Australian and New Zealand Journal of Psychiatry, 40(5), 394-401. 13.

13. Eccles, M., Freemantle, N., \& Mason, J. (1999). North of England evidence-based guideline development project: summary version of guidelines for the choice of antidepressants for depression in primary care. North of England Antidepressant Guideline Development Group. Family Practice, 16(2), 103-111. from http://fampra. oxfordjournals.org/cgi/content/full/16/2/103 14.

14. McManus, P., Mant, A., Mitchell, P.B., Montgomery, W.S., Marley, J., \& Auland, M.E. (2000). Recent trends in the use of antidepressant drugs in Australia, 1990-1998. Medical Journal of Australia, 173(9), 458-462. 15.

15. Department of Health and Ageing. (2005). Australian Statistics on Medicines 2003. Canberra: Australian Department of Health and Ageing. Retrieved from http://www.health.gov.au/ internet/wcms/Publishing.nsf/Content/pbs-pubsasm2003 16. Department of Health and Ageing. (2008). Australian Statistics on Medicines 2006. Canberra: Australian

16. Department of Health and Ageing. (2006) Retrieved from www.health.gov.au/ internet/main/publishing.nsf/content/ pbs-pubsasm

17. Australia second in world in anti-depressant prescriptions. (2017). ABC News. Retrieved from http://www.abc.net.au/ news/2013-11-22/australia-second-in-world-in-anti-depressantprescriptions/5110084

18. Lam R, Levitt A, Levitan R, Michalak E, Cheung A, Morehouse R, Ramasubbu R, Yatham L, Tam E. (2016) Efficacy of bright light treatment, fluoxetine, and the combination in patients with non-seasonal major depressive disorder: a randomized clinical trial. JAMA Psychiatry. ;73(1):56-63. doi:10.1001/jamapsychiatry.2015.2235

19. Ströhle, A. (2009). Physical activity, exercise, depression and anxiety disorders. Journal of neural transmission, 116(6), 777-784.

20. Fergusson, D., Boden, J., \& Horwood, L. (2009). Tests of causal links between alcohol abuse or dependence and major depression. Archives of General Psychiatry, 66(3), 260. http://dx.doi.org/10.1001/archgenpsychiatry.2008.543

21. Patel, I. (2010). Alcohol and depression. InnovAiT.

22. Wu, W., Luh, D., Lin, C., Chiang, Y., Hung, C., \& Wang, S. et al. (2016). Reciprocal relationship between unhealthy eating behaviours and depressive symptoms from childhood to adolescence: 10-year follow-up of the child and adolescent behaviors in long-term evolution study. Public Health Nutrition, 19(09), 1654-1665. http:// dx.doi.org/10.1017/s1368980015003675

23. Sanchez-Villegas, A., \& Martínez-González, M. (2013). Diet, a new target to prevent depression? BMC Medicine, 11(1). http://dx.doi.org/10.1186/1741-7015-11-3

24. Fernandez-Mendoza, J., \& Vgontzas, A. (2013). Insomnia and its impact on physical and mental health. Current Psychiatry Reports, 15 (12), 1-8.

25. Baglioni, C., Spiegelhalder, K., Nissen, C., \& Riemann, D. (2011). Clinical implications of the causal relationship between insomnia and depression: how individually tailored treatment of sleeping difficulties could prevent the onset of depression. EPMA Journal, 2(3), 287-293. http://dx.doi.org/10.1007/ s13167-011-0079-9

26. Fernandez-Mendoza, J., \& Vgontzas, A. (2013). Insomnia and its Impact on Physical and Mental Health. Current Psychiatry Reports, 15(12). http://dx.doi.org/10.1007/s11920-0130418-8 


\subsection{Language that harms}

It is important to take a moment to consider not only the medical conceptualisation of human experience as illness, and the burgeoning use of psychoactive drug treatments, but as well the influence of illness language itself. Words are not merely descriptive, as one might imagine, they are causative, and can have unexpected consequences. There is a saying, 'give a person a label and soon they'll begin to live up to it'. Unnecessarily naming and defining common human experience (however difficult) as 'illness' or 'disorder' can modify the way people perceive themselves (and how others see them and respond to them) and may affect their self-confidence, self-image, and subsequent life choices, negatively. Put plainly, this kind of language serves no positive purpose, and may harm people; yet it is central to mental health literacy content.

Consider the following common trajectory and its compounding factors: an individual reports their experience of distress to a doctor who feels obliged to provide a diagnosis of some kind of disorder (most commonly an affective disorder), a script for medication, and perhaps a referral to a mental health practitioner, requiring a Mental Health Treatment Plan. Factors that may compound this potentially negative trajectory, may, as already mentioned include: a change in self-perception, and in the way that others (such as work colleagues, friends, and family) perceive their diagnosis. The individual may take time off work for recovery, and withdraw from some social responsibilities and socially inclusive activities, further reinforcing their illness status and trajectory. It must be considered here that such compounding factors have potential to create a subtle yet consequential shift from an internal locus of control to an external one: unwitting acquiescence to an illness entity and to those (professionals) who have the only means by which to treat it.

Throughout this cumulative journey, clinical patient records and other documentation mentioning the individual's 'illness' status, may unexpectedly influence their eligibility for insurance, for some forms of future employment, and may colour the responses of subsequent medical service providers, as well as other institutional service providers to whom their 'illness' status becomes known. This potential slippery slope, commencing with the casual issuing of a diagnosis, has attracted too little attention by medical ethicists, though to their credit, many GPs are concerned about this, and are changing their practices. Clearly, mental health literacy is in need of urgent and comprehensive revision.

\section{A Common Patient Journey}

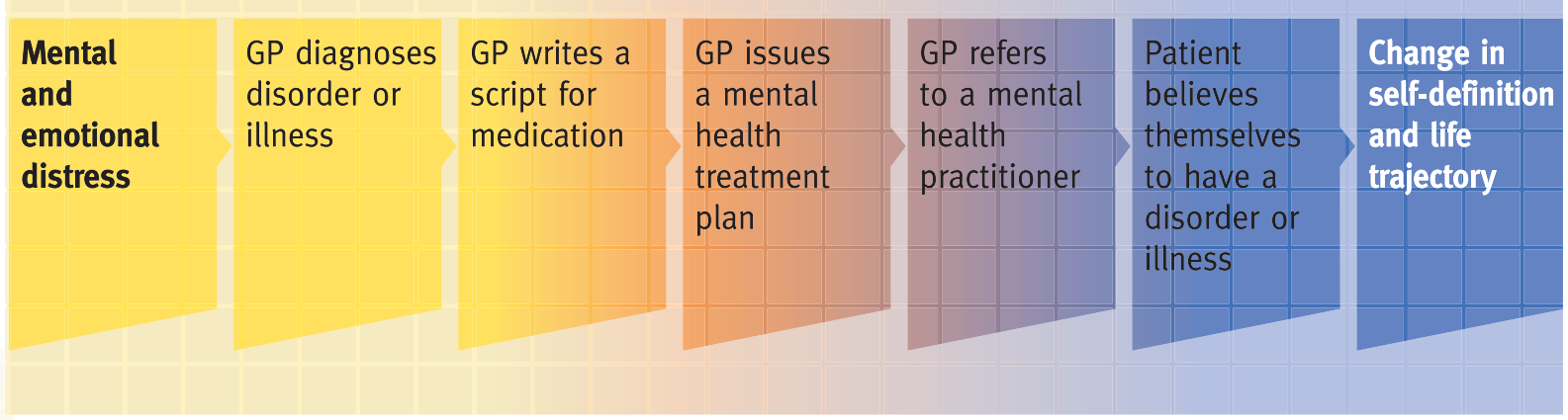

(Figure 1) 


\subsection{An inherently stigmatising narrative}

A central theme of some mental health literacy campaigns is reducing stigma. Such campaigns have employed community education, and considerable use of mass media marketing. Ironically, the core illness narrative of this approach may itself be inherently stigmatising. By poorly distinguishing between the broad spectrum of common (albeit sometimes very difficult and debilitating) human experience, and high intensity low prevalence mental health difficulties - lumping them all in together under 'mental health' and implying mental illness, such campaigns may be inadvertently reinforcing the very stigma they are designed to diminish.

\subsection{De-contextualising human experience}

The current emphases of mental health literacy centre around individual psycho-pathology and its treatment. This individual problem oriented approach tends to de-contextualise the experience of individuals, by ignoring social and other correlates that may be strongly associated with their distress. Such distress will unlikely be remediable with only the symptomatic relief of a conventional treatment approach; broader issues may need to be addressed. Integrating other elements with mental health literacy such as strengths based psychology, or resilience training, has limited merit, because it still weds these elements with a core pathological and individual problem oriented emphasis, ignorant of crucial contextual factors.

Prime examples of broad contextual issues include: unemployment, collapse of local industry, poverty, collective community hopelessness (such as in some indigenous and rural communities), unavailability of affordable housing, delayed and very expensive and stressful family law processes, unhelpful financial services policy and practices during times of drought, and poor disaster recovery responses. More immediate contextual issues might include: family breakdown, lack of social support, unavailable or inadequate local psycho-social non-medical service support, lack of opportunity for personal advancement, financial difficulties, and conspicuous in rural communities, the family divisive issue of succession.

Consideration of contextual factors is also vitally important in suicide prevention. Suicide is a significant and hugely costly public health issue; a public health issue for which a public health approach is needed (not just a clinical one); one that recognises the potentially greater impact of a whole of population approach to prevention, rather than a merely individual problem oriented and reductionist approach focused on treating people with serious mental health difficulties ${ }^{27,28} \mathrm{~A}$ public health approach emphasises an 'upstream' perspective: one that focuses on risk and protective factors in order to prevent the kinds of intense or prolonged distress that can escalate into suicidality, rather than a 'downstream' approach, which focuses on presumed 'illness' or dealing with crises and their aftermath. ${ }^{10}$

10. Ashfield, J., Macdonald, J., \& Smith, A. (2017). A 'situational approach' to suicide prevention: why we need a paradigm shift for effective suicide prevention. Adelaide: Australian Institute of Male Health and Studies \& Western Sydney University. Retrieved from http:// malesuicidepreventionaustralia.com.au/papers/

27. Rosenburg, S., \& Mendoza, J. (2010). Suicide and suicide prevention in Australia: breaking the silence. Lifeline Australia, and, Suicide Prevention Australia.

28. Rose G. Strategy of prevention: lessons from cardiovascular disease. Br Med J (Clin Res Ed). 1981; 282:184751. PMID: 6786649 


\subsection{Discouraging community partnership in preventative mental health}

Despite current mental health literacy campaigns purporting to conscript the public to help with the 'problem' (and the use of slogans like, 'mental health is everybody's business'), ordinary citizens are actively discouraged from all but superficial involvement in preventative mental health, because the current emphasis on mental 'illness' and 'disorder' understandably persuades them to leave it to the professionals. Illness and disorder suggest that a professional medical response and medication are needed, and that the actions of an 'ordinary' individual could carry the potential for making things worse.

There is immense un-tapped potential for meaningful community partnership in the endeavour of psychological support, preventative mental health, and suicide prevention, if we can move past the illness narrative of our present mental health system and mental health literacy. Activating and harnessing the latent interpersonal and therapeutic capacity of communities for preventative mental health: assisting and supporting individuals across a broad range of situations of distress across the life span, could revolutionise the mental health and wellbeing of our society.

Models of more effective community partnership of a kind that begin to diminish the involvement and cost of professional interventionism, already exist. The Trieste model in Italy is one such example - one from which not only are there vital lessons to be learned, but which could be further enhanced with a core narrative that focuses not on illness, but on human experience, and ways of ameliorating its difficulties of distress, through family and community involvement in providing support. ${ }^{29}$ This is not to suggest a model of de-institutionalisation in favour of community care. Such a model does not tackle the problem of pathologising human distress, the mental illness narrative, the growing use of psychotropic drugs, or neglect of community capacity; it merely shifts the same paradigm from institution to community. This may still have some advantages, but these are not infrequently overshadowed by economic opportunism, and poor execution of policy. ${ }^{30,31}$

\subsection{Messaging that assumes available and appropriate clinical pathways and service provision}

Current mental health literacy with its emphasis on recognition of illness and illness symptoms, promotes the idea that once a person is identified as experiencing the distress associated with a mental illness or disorder, they merely need to be referred to an appropriate health professional for support. Mental health literacy heavily assumes and is predicated on the availability of timely and appropriate psychological and mental health support. However, such support is not always available in a timely or appropriate way; in some communities long waiting lists, or poor service quality is the norm.

In others, no service is locally available and must be sought from much further afield. ${ }^{32}$ It can be very frustrating for individuals and communities enthusiastically participating in mental health literacy training like Mental Health First Aid, to discover that getting appropriate help for those they are concerned about is no easy task, and sometimes appears almost impossible, particularly for men needing help. It is by no means clear whether such programs actually have much value; a question being posed not just in Australia but in other countries that have also heavily funded them. ${ }^{33}$

29. Senator Lyn Allison, Chair, Senate Select Committee on Mental Health. (2006). Appendix 3 Report of mental health services observed in Trieste, Italy - January 2006. Canberra: Parliament of Australia. Retrieved from http://www.aph.gov.au/Parliamentary/Business/Committees/Senate/ Former_Committees/mentalhealth/rep

30. Shen, G., \& Snowden, L. (2014). Institutionalization of deinstitutionalization: a cross-national analysis of mental health system reform. International Journal of Mental Health Systems, 8(1), 47. http://dx. doi.org/10.1186/1752-4458-8-47

31. Jones, D. (2010). Commentary: deinstitutionalization of mental health services in South Australia - out of the frying pan, into the fire? Community Health Studies, 9(1), 62-68. http://dx.doi. org/10.1111/j.1753-6405.1985.tb00542.x

32. Mental health in rural areas | RANZCP. (2017). Ranzcp.org. Retrieved from https://www.ranzcp.org/ Publications/Rural-psychiatry/Mental-health-in-rural-areas.aspx

33. The promise and limits of 'mental health first aid' (2017). The Boston Globe. bostonglobe.com Retrieved from https://www.bostonglobe.com/ideas/2015/01/23/the-promise-and-limits-mentalhealth-first-aid/TaSVSJma5TMnHZZzNItYKM/story.html 


\subsection{Problematic for suicide prevention}

The current mental illness narrative evident in mental health literacy messaging, has tended to reinforce the idea that suicide should, in most cases, be considered to be the result of mental illness or disorder. Such a conflation of suicide with mental illness is erroneous. ${ }^{34}$ Whilst conditions like major depression may sometimes be implicated in cases of suicidal ideation and death by suicide, and are an important consideration in the design of appropriate preventative measures, this should not be considered license to assume an association with suicide to a degree that is unsupported by evidence..$^{34}$ Limiting preventive strategies to those built upon the unfounded presumption of mental illness or disorder will simply not help many, perhaps the majority, of those at risk of suicide.

Suicide prevention initiatives that are preoccupied with detection of illness or disorder like major depression may well be putting people's lives at risk, by not attending to forms of distress that don't constitute illness or disorder, and yet which can result in suicidal ideation and suicide. ${ }^{10}$

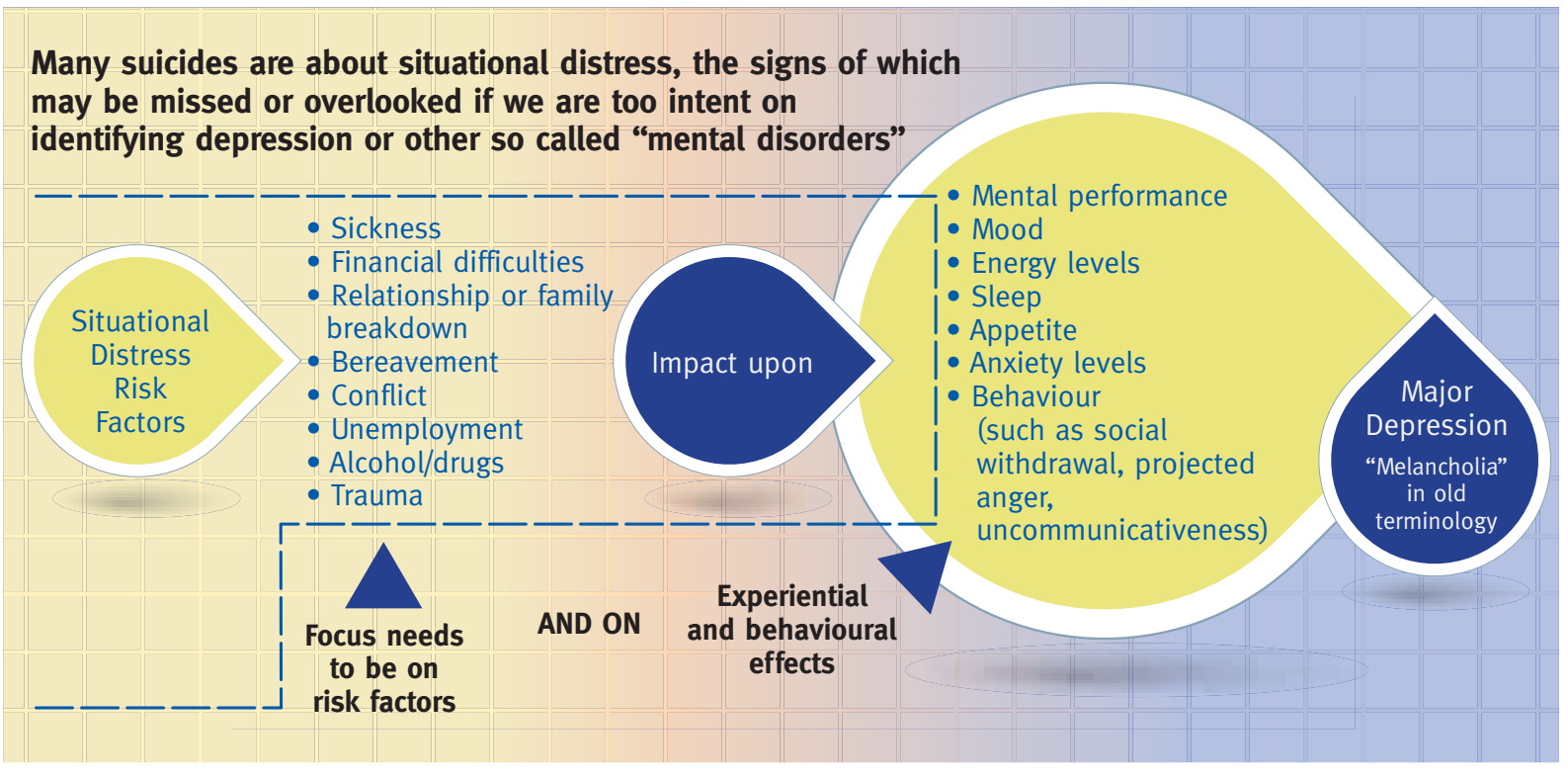

(Figure 2)

\subsection{Lacks gender differentiation and specificity}

Men are not women and women are not men. Though stating the yawningly obvious, this crucial observation is rarely reflected in the content of mental health literacy initiatives, mental health promotion, and direct service delivery methods and approaches. In Western society, in the last several decades, there has been considerable ideological pressure to disconnect understanding of gender from biological reality, resulting in a largely gender generic approach in the way service policy and service delivery have been shaped in mental health. This tends to ignore considerable evidence of gender specific features of physiology, endocrinology, and neurology affecting human behaviour and experience. ${ }^{35,36,37}$ Such genericism also fails to appreciate vital cultural demands and expectations that contribute to shaping gender specific experience and behaviour.

34. Hjelmeland, H., Dieserud, G., Dyregrov, K., Knizek, B., \& Leenaars, A. (2012). Psychological autopsy studies as diagnostic tools: are they methodologically flawed? Death Studies, 36(7), 605-626, from http:// dx.doi.org/10.1080/07481187.201 1.584015

10. Ashfield, J., Macdonald, J., \& Smith, A. (2017). A 'situational approach' to suicide prevention: why we need a paradigm shift for effective suicide prevention. Adelaide: Australian Institute of Male Health and Studies \& Western Sydney University. Retrieved from http:// malesuicidepreventionaustralia.com.au/papers/

35. Kajantie, E., \& Phillips, D. (2006). The effects of sex and hormonal status on the physiological response to acute psychosocial stress. Psychoneuroendocrinology, 31(2), 151-178. http://dx.doi. org/10.1016/j.psyneuen.2005.07.002

36. Taylor, S., Klein, L., Lewis, B., Gruenewald, T., Gurung, R., \& Updegraff, J. (2000) Biobehavioral responses to stress in females: tend-and-befriend, not fight-orflight. Psychological Review, 107(3),411-429. http://dx.doi.org/10.1037/0033295x.107.3.411

37. Ashfield, J. (2014). Doing psychotherapy with men: practicing ethical psychotherapy and counselling with men (1st ed.). Adelaide:

Australian Institute of Male Health and Studies. 
This is far from a merely academic issue. ${ }^{37}$ Take for example the clearly male predominant issue of suicide mortality: most mainstream and generously funded suicide prevention programs still do not appreciate the need for gender specific considerations despite at least $75 \%$ of suicides being male, with many men dying on their first attempt. ${ }^{38,} 39 \mathrm{It}$ is also the case that the majority of men at greatest risk of suicide are not successfully engaged by mental health services. ${ }^{40}$

It is unlikely that ignoring gender considerations hasn't to some degree undermined the success of prevention programs in reducing suicide mortality, given an estimated increase in suicide in the last decade of 42.9 percent. $^{38}$

Consideration of gender based on evidence, and not ideology, is essential in mental health policy, and activities of: preventative mental health, mental health service delivery, mental health literacy, and suicide prevention. Such activities will be deficient and potentially ineffectual unless they take account of gender related socio-cultural demands and expectations, and especially different on-average male versus female:

- bio-behavioural responses to stress

- psychological coping and emotion regulation strategies

- help-seeking behaviours

- communication linguistics

- approaches to problem solving

\subsection{Overwhelms the mental health system with demand}

The unnecessary and inappropriate medicalisation of human distress evident in the mental illness narrative, and articulated through mental health literacy initiatives, may have significant consequences not only for individuals (as already noted), but also for the functionality and economy of the mental health system, estimated to be costing no less than 28.6 billion dollars each year. ${ }^{40}$ That this system is overwhelmed by demand and not serving consumers well is a much-discussed issue amongst the general public and in the media. It should not surprise us that the present mental illness paradigm has led the mental health system into economic and service delivery crisis.

Recognising that many people can be assisted with low intensity mental health difficulties without the costlier engagement of mental health professionals, non-government mental health organisations have been funded to trial or conduct brief intervention programs. These are adaptations of the British, Improving Access to Psychological Therapies (IAPT) model. ${ }^{42}$ This approach uses a strictly manualised Cognitive Behavioural Therapy (CBT) model, that consists of usually a brief number of sessions. However, this approach should raise several concerns: it is still largely in continuity with the present mental illness paradigm, it reinforces an individual problem oriented approach (which often ignores contextual factors), it does not harness the capacity of communities for preventative mental health, and is based on a regimented and manualised model of Cognitive Behavioural Therapy, which itself is attracting

37. Ashfield, J. (2014). Doing psychotherapy with men: practicing ethical psychotherapy and counselling with men (1st ed.). Adelaide: Australian Institute of Male Health and Studies.

38. Australian Bureau of Statistics. (2016). Causes of death, Australia, 2015. Catalogue No. 3303.0. Belconnen, ACT: Commonwealth of Australia. Accessed from http://www.abs.gov.au/AUSSTATS/ abs@.nsf/allprimarymainfeatures/47E19CA15036B04BCA2577570014668B?opendocument

39. Isometsa, E. \& Lonnqvist, J. (1998). Suicide attempts preceding completed suicide. The British Journal of Psychiatry, 173(6), 531-535. http://dx.doi.org/10.1192/bjp.173.6.531

40. McPhedran, S. \& De Leo, D. (2013). Miseries suffered, unvoiced, unknown? communication of suicidal intent by men in "rural" Queensland, Australia. Suicide and Life-Threatening Behavior, 43(6), 589-597.http://dx.doi.org/10.1111/sltb.12041

41. Medibank \& Nous Group (2013) The case for mental health reform in Australia: a review of expenditure and system design. Research Report, Melbourne. (2017).

42. England, N. (2017). NHS England adult improving access to psychological therapies programme. England.nhs.uk. Retrieved from https://www.england.nhs.uk/mental-health/adults/ iapt/ 
attention for its failing effectiveness. One reason advanced as an explanation for this, was the initial placebo advantage first afforded it due to its wide endorsement by government agencies that adopted it. The effects of CBT have apparently declined linearly and steadily since its introduction, as measured by patients' self-reports, clinicians' ratings, and rates of remission. ${ }^{43}$

The IAPT styled approach may also be problematic because it ignores the voluminous trans-theoretical research data suggesting the limited effectiveness of CBT compared for example with the common factor of therapeutic alliance which has been shown to have twice the efficacy of CBT in achieving positive outcomes in therapy. ${ }^{44,45}$ There also needs to be better studies designed to assess the long-term effectiveness of the AIPT approach. These will need to cut through the positive spin generated by training organisations and service delivery agencies benefiting from proliferating the model, to ascertain whether it is merely a stop-gap measure that results in the false economy of a revolving door syndrome: the tendency of clients to get better for a while, and then end up returning to the system for further help, because their issues were not effectively addressed.

43. Johnsen, T. \& Friborg, O. (2015). The effects of cognitive behavioral therapy as an anti-depressive treatment is falling: a meta-analysis. Psychological Bulletin, 141(4), 747-768, from http://dx.doi. org/10.1037/bul0000015

44. Hubble, M., Duncan, B., \& Miller, S. (2006). The heart and soul of change (1st ed.). Washington. D.C.: American Psychological Association.

45. Duncan, Barry L., Miller, Scott D., Wampold, Bruce E. \& Hubble, Mark A. (eds.) (2010) The heart and soul of change: delivering what works in therapy (2nd ed.). Washington, D.C.: American Psychological Association, from http://dx.doi.org/10.1037/12075-000 


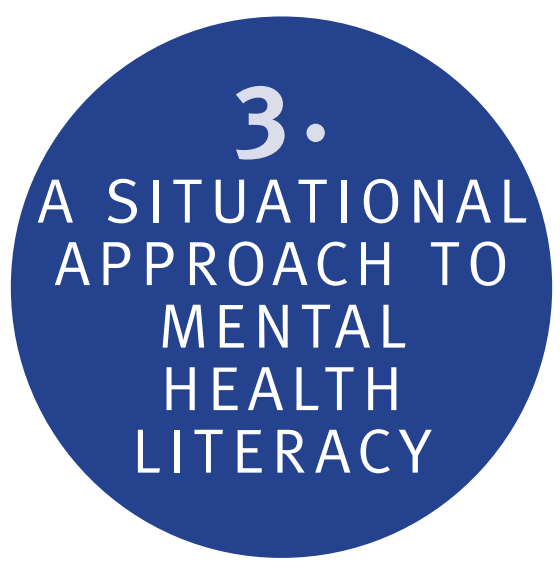

\subsection{Defining the situational approach}

A situational approach to mental health literacy, centres around the idea of situational distress which encompasses a significantly challenging or troubling mixed experience of mind, thoughts, emotions, bodily sensations, or behaviours, most often associated with an apparent challenging or decompensating life event, such as bereavement, a change in health status, relationship breakdown, financial, or occupational difficulties. This distress may significantly overlap with many of the symptoms usually taken to suggest mental 'illness' or 'disorder' (such as those associated with depression and anxiety). Even when distress is sometimes inexplicable, a situational approach discourages any presumption of illness or disorder.

The situational approach to mental health literacy is chiefly concerned with the broad spectrum of difficult and challenging life events and human experiences across the lifespan, and how these can be responded to in the most effective way to promote quality of life for individuals, as well as enhancing their capacity to meaningfully participate in and contribute to human community. This approach emphasises the importance of normalising human distress and encouraging constructive, effective, and non-pathologising responses to it. This will always mean seeing human experience in the context of gender specific considerations. Additionally, integral to this approach is an appreciation of contextual factors that potentially impinge on the mental health and wellbeing of individuals, families, and communities - factors that may need to be simultaneously addressed along with individuals' experience of distress.

The situational approach emphasises the vital importance of building community capacity for taking a primary role in promotion, prevention, and early intervention for mental health and suicide prevention, with mental health and other allied health professionals complementing these efforts. It also encourages lobbying and gaining the support of Government, corporate industry, and community leaders in addressing: needed improvement in social and mental health policy, and broader issues of contextual change to enhance mental health and wellbeing at the population level. ${ }^{46,47}$

This approach does not downplay the importance of professional expertise in mental health, but proposes that this expertise be refocused, so that people with complex and very challenging mental health difficulties, are properly supported in environments and ways that focus on self-efficacy and recovery, without being unduly pathologised or diminished in dignity. However, at the same time, this approach proposes the activation of new sources of capacity - both community and professional, for promotion, prevention, and early intervention for mental health, and emphasises the importance of altering the balance of preventative mental health and suicide prevention with primary and secondary prevention being given primacy.

46. Toomey, A. (2009). Empowerment and disempowerment in community development practice: eight roles practitioners play. Community Development Journal, 46(2), 181-195. http://dx.doi.org/10.1093/ cdj/bsp060

47. Cargas, S. (2011). Human Rights from Below: Achieving Rights Through Community Development by Jim Ife. Journal Of Human Rights, 10(2), 243-246. http://dx.doi.org/10.1080/14754835.2011.569303 


\section{Normalising Human \\ Distress}

\section{Contextualising Human Distress}

\section{Promoting Language \& Definitions in Mental Health that Preserve People's Dignity} Community Capacity Building Education for Preventative Mental Health and Suicide Prevention

\section{Gender Differentiation \& Specificity}

\section{De-Mystifying High Intensity Mental Health Difficulties}

Identifying a broad spectrum of difficult and challenging life events and human experiences across the lifespan, and encouraging constructive, effective, and non-pathologising responses to them.

Exploring events and factors that potentially impinge on the mental health and wellbeing of individuals, families, and communities - factors that may need to be simultaneously addressed along with individuals' experience of distress.

Replacing the language of illness and disorder in mental health with new language and definitions to describe and respond to experiences of distress and mental health difficulties.

Providing psychological literacy education to communities across a broad range of life challenges. Training in peer support, lifestyle factor change, and referral brokerage - how to match psychosocial needs with professional support and services (should this be needed), and assisting communities to be discerning in the utilisation of professional services, and to be informed and critical consumers.

Ensuring that all levels of community, workforce, and professional education for mental health, and in all mental health service delivery, and suicide prevention activities, the importance of gender differentiation and specificity is emphasised.

Explaining and framing high intensity mental health difficulties in the most non-pathologising and simple way possible, and urging accountability of mental health service approaches for ensuring excellence of any support or intervention provided. Demystifying high intensity mental health difficulties in order to encourage greater community support and engagement with individuals for them to attain the highest level of wellness of which they are capable.

\section{Workforce Education and CPD}

Educating mental health and human service professionals, and other relevant workforces, in the situational approach to mental health promotion and suicide prevention.

Emphasis on Promotion, Prevention \& Early Intervention for Mental Health, Primary \& Secondary Prevention in Suicide Prevention

Lobbying Government, Corporate Industry, and Community Leaders

\section{Supporting Change in Primary Care}

Encouraging a focus on 'up-stream' initiatives of preventative mental health and suicide prevention, emphasising primary and secondary prevention initiatives, in appropriate balance with tertiary prevention.

Seeking to address broader issues of contextual change to enhance mental health and wellbeing at the population level. Seeking policy change to improve mental health and suicide prevention initiatives and services.

Supporting GPs to refocus and adopt a situational approach, by abandoning illness labelling of distress and mental health difficulties, by: adopting a new assessment approach that includes contextual considerations, changing referral and prescribing practices, and by utilising counselling and psychotherapy services in preference to high acuity mental health services, whenever these are not clearly indicated. 


\subsection{Normalising human distress}

The situational approach to mental health literacy includes: identifying and normalising a broad spectrum of difficult and challenging life events and human experiences across the lifespan, and encouraging a constructive, effective, and non-pathologising response to them.

This approach advocates promoting more strongly evidence based definitions of difficulties like depression, developing appropriate screening criteria, and breaking the conflation of depression and mental illness with suicide and suicide prevention initiatives. Normalising and de-pathologising much human experience should also prompt a corresponding and significant change in psycho-tropic drug prescribing practices (and their associated cost), in primary care.

Situational distress may significantly overlap with many of the symptoms usually taken to suggest mental 'illness' or 'disorder' (such as those associated with depression and anxiety). Even when distress is sometimes inexplicable, a situational approach discourages any presumption of illness or disorder.

\section{Potentially Challenging or Decompensating Life Events Associated with Situational Distress}

\section{Bereavement}

III-health (self or a loved one)

Relationship Breakdown

Family Breakdown

Difficulties of Access to Children

Unemployment

Work-related Stress

Financial Difficulties

Housing Crisis

Major Life Transitions

Self-identity or Sexual Identity Issues

Interpersonal Conflict

Meaninglessness or Powerlessness Relating to

One's Occupation, Relationship, or Life

Experience of Disaster or Adverse Climatic Event

Impasse Relating to Succession

Social Isolation or Exclusion

Loneliness

Failure in Business

Poverty

Community in Decline

Lack of Occupational Opportunities

Lack of Opportunities for Meaningful

Relationships

Psychological Trauma

\section{MAY GIVE RISE TO CHANGES IN}

Mental

Performance

Anxiety levels

Self-confidence

Mood

Experience of

Pleasure

Sleep

Appetite

Perception \&

Thought Processes

Energy levels

Behaviour

Mental Outlook

Irritability

Vigilance 


\subsection{Contextualising human distress}

The situational perspective of mental health and mental health literacy, though focused on the experience of individuals, also encompasses contextual and systemic factors. It endeavours to explore factors that potentially impinge on the mental health and wellbeing of individuals, families, and communities - factors that may need to be simultaneously addressed along with individuals' experience of distress.

The extent of contextual considerations may include: challenging or decompensating life events, local community issues and events affecting the experience and mental health of individuals, and broader regional, State, or National events and influences, including such things as unemployment, drought, economic conditions, industry viability, and social and health policy. Few of these things are beyond the power of communities to influence, if they are conscripted into preventative mental health efforts, suicide prevention, and initiatives designed for community development. Local members of parliament and Senators can be enlisted for and empowered to execute their office through such community initiatives. ${ }^{48}$

\section{Dual focus of a situational approach}

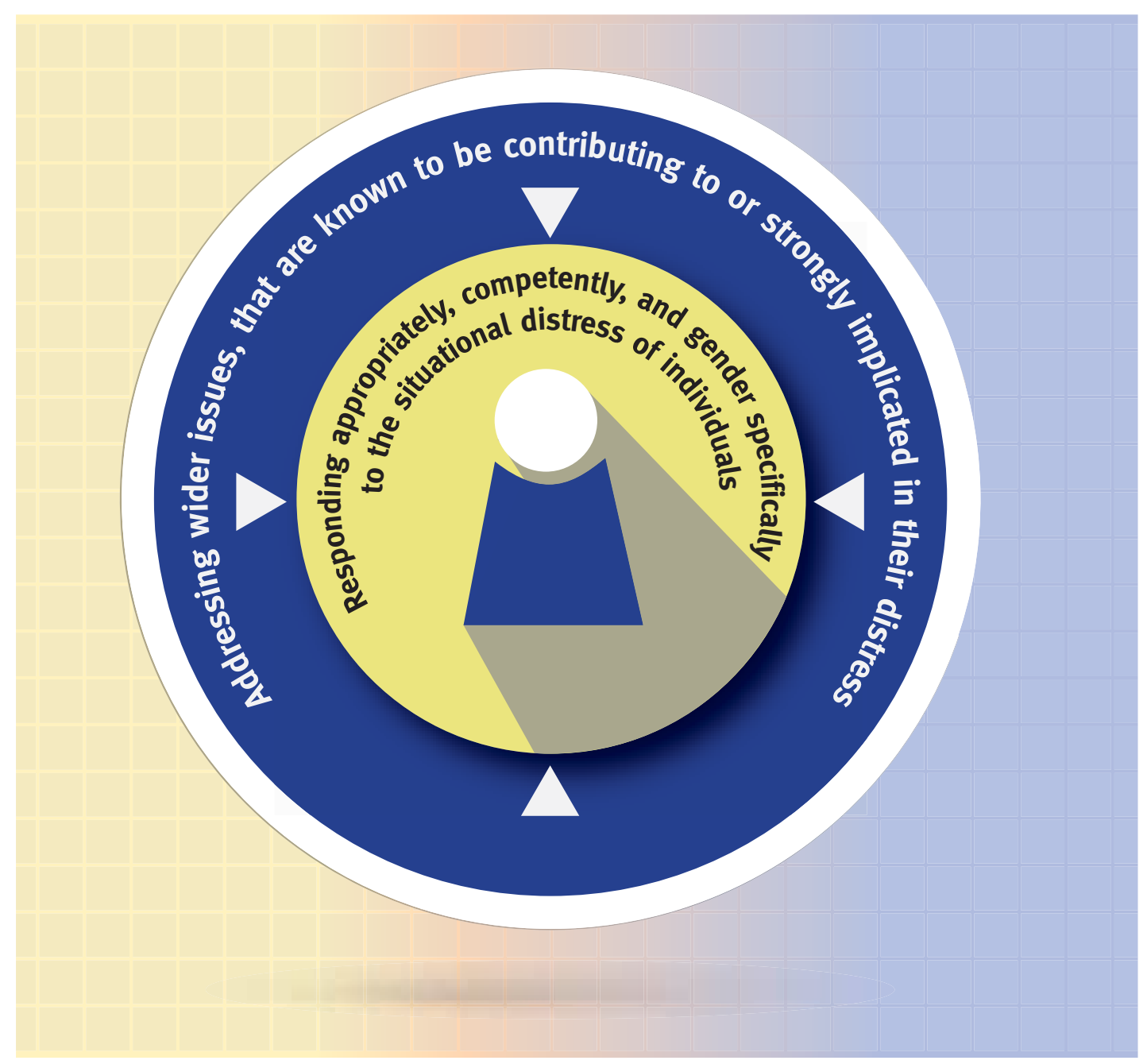

(Figure 4)

48. Pathways to Despair: The Social Determinants of Male Suicide (aged 25-44), Central Coast, NSW. MHIRC Paper no. 2. Penrith: MHIRC. http://www.uws.edu.au/_data/assets/pdf_file/0015/217032/ MHIRC_2.Pathways.pdf 


\subsection{Promoting language \& definitions in mental health that preserve people's dignity}

Of prime importance in a situational approach to mental health literacy is initiating and promoting changes in language and definitions used in relation to human experience and mental health. This is critical to treating people with respect, preserving their dignity, and avoiding doing harm. It should also be noted that appropriate language used in mental health can also contribute to building individuals sense of personal agency and hope, and can result in empowerment. ${ }^{49}$

Debate about the idea of mental illness has been ongoing for many years; although this has been restricted to mainly academic circles. Some critics of the mental illness/mental health perspective argue that this wrongly frames ordinary, albeit sometimes very challenging and painful human experience or distress as illness, when it isn't illness at all. They argue that there is no such thing as mental illness, only physical illness. If an organic, bio-chemical, or physical cause is responsible for disrupted emotional or mental functioning or behaving in an unusual, unsafe, or self-defeating way, that is simply a physical illness or process that is having unwanted effects in a person's experience and behaviour, not a mental illness. Further, they argue that not only is the notion of 'mental illness' untenable, it is central to a pathologising paradigm that represents

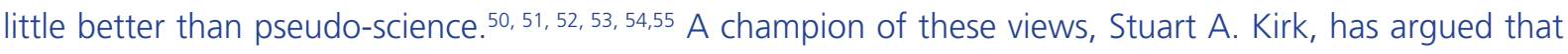
psychiatry is clearly a failed enterprise, because the prevalence of what has been termed 'mental illness' has escalated not diminished, with about $20 \%$ of adult Americans diagnosable as mentally ill in $2013 .{ }^{56}$

The stance assumed in a situational approach to mental health literacy, whilst critical of the current dominant paradigm of mental illness and the mental health system, is one of pragmatism. For now, it is simply impractical to suggest that we dispense with the term mental health (despite its implied opposite: illness), because it is so entrenched. However, it is practicable to adopt other changes of language, and to promote alternative ways of conceptualising and responding to human distress - including in its most challenging forms, which the situational approach terms: high intensity mental health difficulties.

The term mental health needs to be retained (at least for now), since it is firmly embedded in professional, academic, literary, and common public use as a broad and pivotal term. It also provides a familiar and provisional starting point implying some sort of desirable mental, emotional, and behavioural quality of wellness. For practical purposes, a definition of mental health might suggest:

An agreeable and functional quality of everyday experience involving one's mental activity, emotions, physiology, reflexive and behavioural responses and capacities.

An undesirable disruption of this experience - a disruption of mental health may be simply called: a mental health difficulty, what psychiatrists refer to (especially where this is severe) as 'mental disorder' and 'mental illness'. The severity of this difficulty can be registered as either a low intensity mental health difficulty or a high intensity mental health difficulty, thus avoiding the words disorder and illness altogether. This substitution of language may preserve people's dignity by avoiding harmful labelling, at the same time avoiding trivialising complex difficulties - the experience of which may on occasions be acutely painful, profoundly distressing, debilitating, or disruptive.

49. Hungerford, C., Hodgson, D., Clancy, R., \& Mon. (2016). Mental Health Care: An Introduction for Health Professionals in Australia (1st ed.). John Wiley \& Sons.

50. Tom Burns (2006). Psychiatry: a very short introduction. Oxford University Press. pp. 93-99. 51. Henry A. Nasrallah (2011). The antipsychiatry movement: who and why PDF. Current Psychiatry. Mervat Nasser (1995). The rise and fall of anti-psychiatry PDF. Psychiatric Bulletin.

53. Dain, Norman (1994). Psychiatry and anti-psychiatry in the United States. in Micale, Mark S.; Porter, R. Discovering the history of psychiatry. Oxford \& New York: Oxford University Press. pp. 415

54. Warme, Gordon (2006). Daggers of the mind: psychiatry and the myth of mental disease. Canada: House of Anansi.

55. Ross, Colin (1995). Errors of logic in biological psychiatry in Colin R., and Alvin P. Pseudoscience in Biological Psychiatry. NY: Wiley \& Sons. pp. 85-128.

56. Kirk, Stuart A. (2013). Mad science: psychiatric coercion, diagnosis, and drugs. Transaction Publishers. p. 326. 
To clarify further: anyone can experience a mental health difficulty; and everyone likely will at some stage of their lives. A mental health difficulty in most cases does not emanate from a physical illness or disorder. It is a common human challenge to be managed and worked with creatively and constructively, including sometimes with the use of psychotherapy, and yes, medication, should that genuinely have something to contribute.

A Low Intensity Mental Health Difficulty interferes with a person's usual or preferred mental, emotional, and social capacity, and perhaps as well, their experience of feeling capable and competent.

Low intensity mental health difficulties are usually associated with difficult life events and challenges, like: unemployment, sickness, loss and grief, money troubles, relationship difficulties, conflict, and stress. Low intensity mental health difficulties are common and are usually resolved through a person's own coping ability, adjustments to lifestyle, and the support of friends and family. Of course, professional help may also be important, particularly if a person becomes 'stuck' and can't seem to recover or move forward.

A High Intensity Mental Health Difficulty usually significantly impairs a person's ability to function on a day to day basis and noticeably interferes with their usual or preferred mental, emotional, or social capacity, and their experience of feeling capable and competent.

Such a difficulty usually requires more than a person's own coping ability, lifestyle adjustments, and support of friends and family. At least initially, it may require thoughtful observation and tentative assessment by a qualified health professional (a doctor, psychotherapist, psychologist, or, in some cases a psychiatrist), who will also suggest and perhaps provide appropriate psychotherapy (psychological therapy).

In some cases, a General Medical Practitioner or Psychiatrist will also recommend prescription medication, which should be carefully considered for its potential to harm, evidence supporting its effectiveness (efficacy), and its appropriateness for the difficulty. If prescribed, it should be regularly reviewed both for any side-effects, and for whether it is genuinely helpful or still necessary.

With any mental health difficulty requiring professional support, professional observations and any assistance given will generally need to be documented, and shared with other professionals. Though it may take more effort to avoid pathological illness categories and language, this is by no means insurmountable. With thought, alternative ways of making observations and communicating with other professionals can be adopted.

What is being suggested here is not really that radical, though it may be difficult to do in some settings, particularly in which traditional diagnostic and illness language use is entrenched. Nonetheless, it is important to endeavour to change the status quo in our institutions and places of work, and the experience of patients and clients, to that of one characterised by respect for their dignity, and the desire to do them no harm. 


\section{Terms and their Relationships in Situational Mental health Literacy}

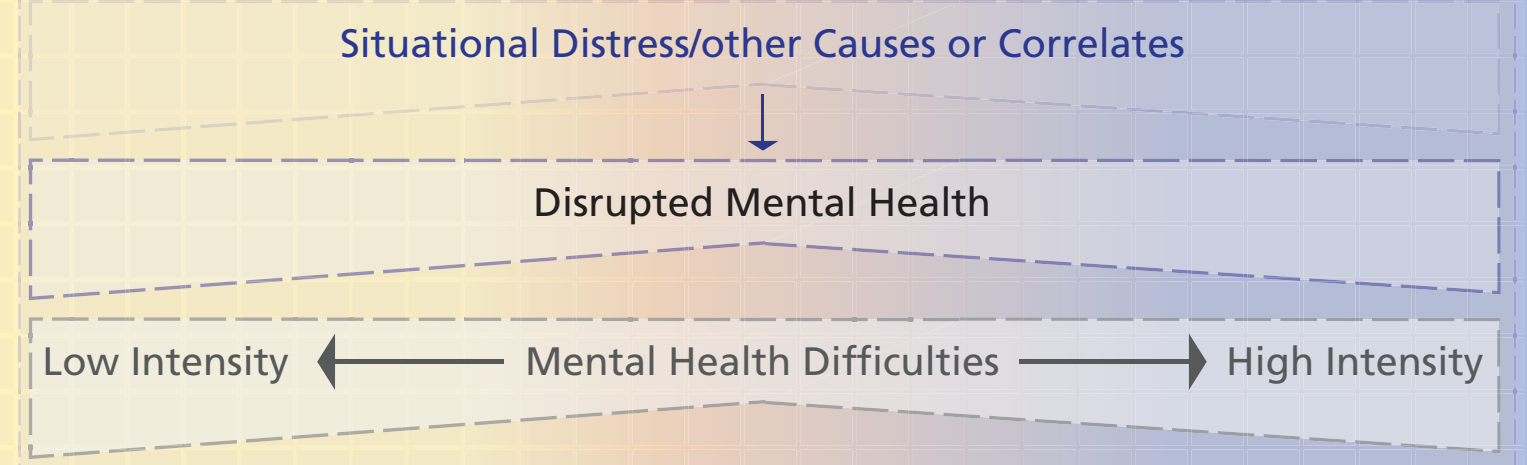

\section{Current Illness/Disorder Spectrum}

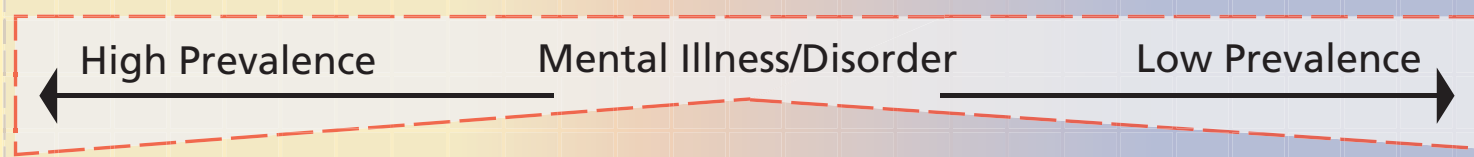

(Figure 5)

\subsection{Community capacity building education for preventative mental health and suicide prevention}

Providing psychological literacy education to communities across a broad range of life challenges, training in peer support, lifestyle factor change, and basic referral brokerage - how to match psycho-social needs with professional support and services (should this be needed), are vital elements in the situational approach.

As already noted, this approach reconceptualises a broad spectrum of human distress, as non-illness, and remediable largely with non-medical intervention. In so doing, it also opens up a whole new potential for meaningful community engagement: activating and harnessing the latent interpersonal and therapeutic capacity of communities for preventative mental health and suicide prevention; enabling them to assist and support individuals with a broad range of situations of distress across the life span.

This reconfiguration may potentially remove a significant burden of service demand and cost from our overwhelmed mental health system - particularly services that currently deal with high prevalence mental health difficulties, and may much better serve consumers whether with low or high intensity mental health difficulties. 


\section{KEY PRIORITIES OF COMMUNITY CAPACITY BUILDING EDUCATION}

\section{Psychological Literacy Education}

Peer Support Training
Engaging with communities, employers, and organisations in providing practical, gender specific, and self-help oriented psycho-education. Such education will focus on a broad range of events and challenges across the life- span, clarifying and exploring helpful responses to them, for individuals, families, and communities to be able to take care of their mental health and know how to deal with psychological distress constructively and appropriately.

Producing and disseminating informative self-help literature which avoids medicalising and pathologising concepts and language, and is tailored and targeted. Much current literature reinforces an illness narrative, is too complex or generic, and lacks sometimes much needed informed and evidence based gender specificity. Ideally, such literature should be evaluated for its effectiveness in not just informing people but also prompting behavioural change.

\section{Lifestyle Factor Change for Mental Health}

Initiating preventative mental health peer support and suicide prevention education programs in communities and organisations, in order to embed trained individuals to be the 'eyes and ears on the ground', able to detect and provide timely support to people in distress, and, if needed, referral to an appropriate professional service provider.

\section{Referral Brokerage and Referral Pathway Training}

Educating communities and organisations in up-to-date information and strategies relating to lifestyle changes that are both preventative and remedial in relation to mental health.

Educating communities and organisations in matching psycho-social needs with appropriate and available professional support and services.

This will involve direct involvement of local consumers and service providers in an honest appraisal of the nature and accessibility of services. This should identify service gaps and deficiencies, and will provide a basis for service redesign. This should also include educating and supporting individuals in becoming more discerning consumers. These strategies will meet with tokenism unless there are reliably monitored accountability criteria for service providers, and genuine broadly representative consumer involvement.

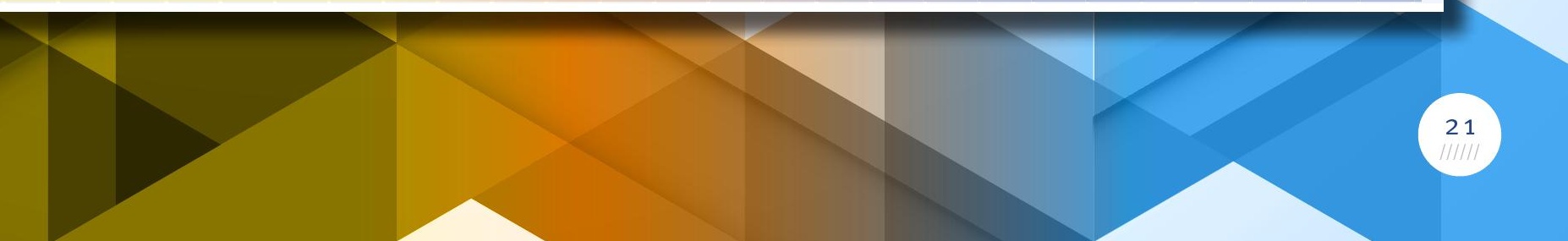




\subsection{Gender differentiation and specificity}

A situational approach to mental health literacy includes a core requirement of ensuring that all levels of community, workforce, and professional education for mental health, and in all mental health service delivery, and suicide prevention activities, the psycho-social nature of gender differences are considered. Evidence about gender specific features of physiology, endocrinology, and neurology affecting human behaviour and experience, and an understanding of socio-cultural demands and expectations that contribute to shaping gender specific experience and behaviour, provides vitally important practical insights for promoting mental health.

An understanding of gender differences can significantly enhance the capacity of women and men to understand and make sense of each other's experiences and behaviour, and can equip them with a capacity to offer each other much more appropriate and effective support - especially in times of distress. Such knowledge is especially important in prevention and early intervention responses focused on issues such as self-harm, suicide, bereavement, homelessness, and unemployment, which have distinctive gender specific implications.

\subsection{De-mystifying high intensity mental health difficulties}

A situational approach to mental health literacy, though emphasising the normalisation of human experience and behaviour, far from downplaying high intensity mental health difficulties, calls for their demystification: explaining and framing these difficulties in the most non-pathologising and simple way possible, as well as urging accountability of mental health service approaches for ensuring excellence of any support or intervention provided. Demystifying high intensity mental health difficulties in the context of mental health literacy should also serve to encourage greater community support and engagement with individuals for them to attain the highest level of wellness of which they are capable.

Reconfiguring service responses in the manner that was discussed earlier, should provide new capacity and resources for traditional mental health service providers working with people with severe conditions, to review, modify, and improve their approach.

\subsection{Workforce education and continuing professional development (CPD)}

Educating mental health and human service professionals, and other relevant workforces (whose role or function has implications for the mental health of individuals) in the situational approach to mental health literacy, will be essential. This will also need to include a non-ideological and evidence supported understanding of gender differences; something of vital importance to all mental health related activities and service provision.

Support of existing employing institutions and agencies in this endeavour will be needed, and in some cases, will need to be a mandated CPD activity. A train the trainer model could be utilised to facilitate this objective without delay, and for as long as it is needed. 


\subsection{Emphasis on promotion, prevention, and early intervention for mental health, and primary and secondary prevention in suicide prevention}

Encouraging a focus on 'up-stream' initiatives of preventative mental health and suicide prevention, emphasising primary and secondary prevention initiatives, in appropriate balance with tertiary prevention, is also central to a situational approach. ${ }^{57}$

In the year 2000, the Australian Commonwealth Government published a new model of Promotion, Prevention, and Early Intervention for Mental Health. Suffering the same fate as some other reform initiatives not adequately funded or executed, it quickly disappeared into the mists of time. However, this document did at least demonstrate, with supportive evidence, that creative and alternative preventative mental health strategies of primary and secondary prevention, rather than just focusing on tertiary prevention and crisis oriented initiatives, should be a centrepiece of reform. ${ }^{58}$

Seventeen years later, we are faced with much the same choice: to continue to support an orientation that is preoccupied with tertiary approaches, chronic and high intensity mental health difficulties and crisis intervention, or shift the proportionality of emphases, to those that reflect the good sense of putting substantial resources into primary and secondary prevention. The situational approach asserts the true economic pragmatism of this shift of emphases. Only with this kind of reform will an overwhelmed and very costly mental health service sector find its way to economy and appropriate relevance.

\subsection{Lobbying government, corporate industry, and community leaders}

A situational approach to the mental health literacy emphasises seeking to address broader issues of contextual change to enhance mental health and wellbeing at the population level. This means engaging with communities, corporate industry, and governments to address local, regional, and national issues of consequence to mental health and suicide prevention, which will include seeking policy change to improve mental health and suicide prevention initiatives and services.

With Commonwealth support, Primary Health Network service commissioning organisations could be mandated to adopt reform criteria of the situational approach in the process of funding preferred service providers of mental health services and suicide prevention, and in properly auditing and evaluating outcomes to ensure integrity of compliance. Lobbying to see a remodelling of service design and delivery requirements for all State and local government providers and mental health promotion organisations, would also be focus of this approach.

\subsection{Supporting change in primary care and broadening referral options}

Consistent with a situational approach to mental health literacy would be supporting GPs to adopt new practices in response to low and high intensity mental health difficulties and the broad range of situational presentations that do not require diagnostic categorisation or medication. This would include abandoning illness labelling of distress and mental health difficulties, and government abolishing Mental Health Treatment Plans in favour of: adopting alternative MBS item numbers for a new assessment and referral approach that includes utilising counselling and psychotherapy services in preference to high intensity mental health services, whenever these are not clearly indicated.

57. Putting prevention into practice guidelines for the implementation of prevention in the general practice setting (2nd ed.). (2017) Melbourne. http://www.racgp.org.au/download/documents/ Guidelines/Greenbook/racgpgreenbook2nd.pdf

58. Commonwealth Department of Health and Aged Care (2000). Promotion, prevention and early intervention for mental health a monograph. Canberra. 
Including counsellors and psychotherapists in the repertoire of subsidised service providers (along with psychologists, mental health nurses, social workers, and occupational therapists), could be financially offset by all non-health care card holders being required to make part payment for any psycho-social allied health service. The counselling and psychotherapy disciplines are philosophically little prone to (and tend to oppose) pathologising distress and mental health difficulties, and could have a new part to play in primary and secondary prevention service delivery initiatives, as well as mental health literacy education (for a definition of counselling and psychotherapy, see Terms and definitions). ${ }^{59}$

Counselling and psychotherapy are presently disciplines least valued in the realm of mental health due to the way current government policy is framed, and their ineligibility for MBS and Better Access to Mental Health Care endorsement, despite many of them holding degree and post-graduate degree training. Many universities are now offering degree and masters level courses in counselling and psychotherapy. There could of course be exclusions for those without requisite degree training.

Establishing partially subsidised user-pay services in the field of mental health, would likely see these services more valued, and could allow a significant expansion, without cost, of new referral options for GPs and new services for consumers. Another advantage of subsidised user-pay services is that greater quality control exercised by consumers may potentially improve service standards by comparison and competition, because consumers may be more discerning and can exercise more choice if they are paying towards the cost of services.

Presently consumers can seek out private full fee for service counselling, psychotherapy, and psychological services, without a doctor's referral or Mental Health Treatment Plan, but this is not an option that is usually suggested, because the most common pathway of referral for doctors is into mostly free or highly subsidised services provided by State or Federal governments. It is also the case, that often, the kind of early support that people need which could be provided by counsellors, for example, is unavailable, because counselling receives no subsidy, and counsellors in private practice struggle to survive. So, despite many people recognising they could probably work through and manage their situational distress, with some skilled support, such support is often not readily available, at least in a subsidised way, and is thus much less likely to be recommended by their GP. There is a need for reform in how allied health professionals are endorsed and subsidised by governments, and recognised by commissioners of public employment.

For greater access to counselling, psychotherapy, and other mental health related allied health services, video-conferencing could be much better utilised as a technology than it is currently, particularly to make services available for GPs to refer into for consumers in rural, remote, and other communities that are not well serviced under existing arrangements. Services would need to be included under the present Better Access to Mental Health Care funding provisions for private allied health practitioners - including counsellors and psychotherapists. 
Relationship (and approximate proportionality) of Elements of a Situational Approach to Mental Health and Mental Health Literacy

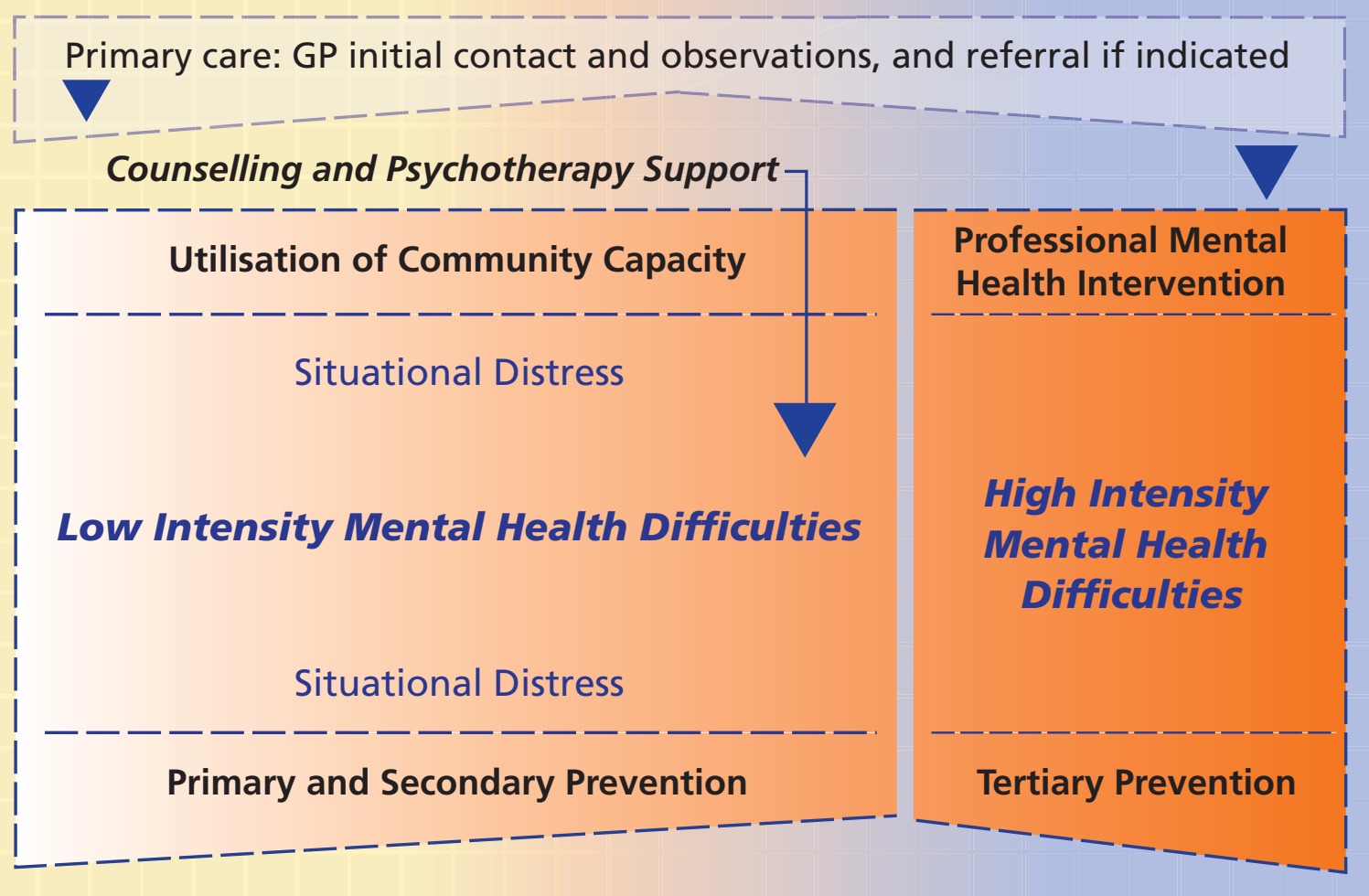

(Figure 6)

This document has sought to offer a critique of existing mental health literacy (and some of its unintended effects), as well as offering a viable alternative situational approach. Though this does not (nor is it intended to) constitute a comprehensive treatment of the subject, it may begin to inform much needed consideration of policy reform in mental health, and should engage mental health professionals in considering the implications of their present practice.

What has been suggested as an alternative to current mental health literacy, is pragmatic, immediately practicable, and well within the scope of a short time-frame for policy formulation and implementation. Though it does pose a particular challenge to established mental health literacy training curricula, where there is scope to improve conditions for mental health consumers, change is an ethical imperative.

Due to the modest scope and intention of this document, some issues that may be considered important may well have been overlooked; it may also have raised as many questions as it has sought to address. Nevertheless, if it can stimulate an honest and incisive discourse about future mental health literacy initiatives, it will have served an important purpose.

The companion to this document is: Ashfield, J., Macdonald, J., \& Smith, A. (2017). A 'Situational Approach' to Suicide Prevention: Why we need a paradigm shift for effective suicide prevention. Adelaide: Australian Institute of Male Health and Studies \& Western Sydney University. Retrieved from http:// malesuicidepreventionaustralia.com.au/papers/ 


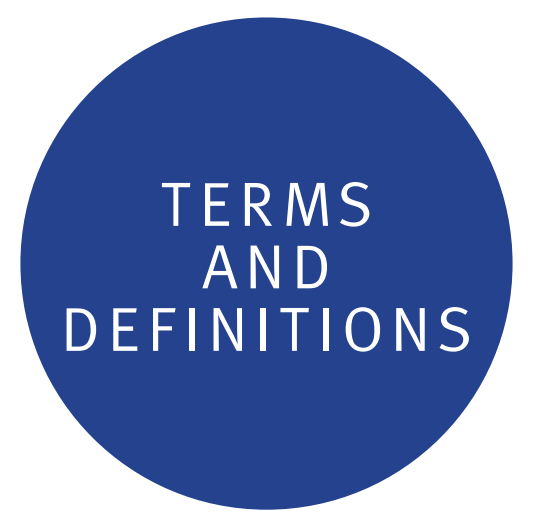

\section{Counselling and Psychotherapy}

Psychotherapy and Counselling are professional activities that utilise an interpersonal relationship to enable people to develop self-understanding and to make changes in their lives. Professional counsellors and psychotherapists work within a clearly contracted, principled relationship that enables individuals to obtain assistance in exploring and resolving issues of an interpersonal, intrapsychic, or personal nature. Professional Counselling and Psychotherapy are explicitly contracted and require in-depth training to utilise a range of therapeutic interventions, and should be differentiated from the use of counselling skills by other professionals.

\section{Professional Psychotherapy/Counselling:}

- Utilise counselling, psychotherapeutic, and psychological theories, and a set of advanced interpersonal skills which emphasise facilitating clients' change processes in the therapeutic context. This work with client processes is based on an ethos of respect for clients, their values, their beliefs, their uniqueness, and their right to self-determination.

- Require in-depth training processes to develop understanding and knowledge about human behaviour, therapeutic capacities, and ethical and professional boundaries.

- Take account of the cultural and socio-political context in which the client lives and how these factors affect the presenting problem. This includes awareness and assessment of social and cultural influences such as age, development, (dis)ability, religion, cultural identity, Indigenous identity, sexual orientation, socioeconomic status, nationality, and gender. Professional Psychotherapists and Counsellors value such differences and avoid discrimination on the basis of these aspects of identity.
- May involve intervening with current problems, immediate crises, or long-term difficulties. The work may be short-term or long-term, depending on the nature of the difficulties, and may involve working with individuals, couples, families, or groups.

- Counselling and Psychotherapy occur in a variety of contexts in the public and private sectors.

- Regard ongoing clinical supervision, professional development, self-awareness, self-development, self-monitoring and self-examination as central to effective and ethical practice. Such practices lead to enhanced capacity to utilise the self of the practitioner effectively in the therapeutic relationship.

Although Counselling and Psychotherapy overlap considerably, there are also recognised differences. While the work of Counsellors and Psychotherapists with clients may be of considerable depth, the focus of Counselling is more likely to be on specific problems, changes in life adjustments and fostering clients' wellbeing. Psychotherapy is more concerned with the restructuring of the personality or self and the development of insight. At advanced levels of training, Counselling has a greater overlap with Psychotherapy than at foundation levels. ${ }^{58}$

\section{Distressing Human Experience}

Describes changes in: mental performance, anxiety levels, self-confidence, mood, experience of pleasure, sleep, appetite, perception and thought processes, energy, behaviour, mental outlook, irritability, and vigilance, which may impair daily functioning or interferes with a person's usual or preferred mental, emotional, and social capacity, and perhaps as well, their experience of feeling capable and competent. Distressing human experience may overlap with many symptoms usually taken to suggest mental illness or disorder. 


\section{Mental Health}

A definition of mental health may encompass: an agreeable and functional quality of everyday experience involving one's mental activity, emotions, physiology, reflexive and behavioural responses, and capacities.

\section{Mental Health Difficulties - Low Intensity, and High Intensity}

As an alternative to the use of illness or disorder references in the fields of mental health and suicide prevention, a disruption of mental health may simply be called - a mental health difficulty, encompassing the broad spectrum of emotional and mental functioning psychiatrists refer to as 'mental disorder' and 'mental illness'. The severity of this difficulty can be registered as either a low intensity mental health difficulty or a high intensity mental health difficulty. This simple substitution may help preserve people's dignity and enhance their wellbeing, whilst at the same time not trivialising complex difficulties the experience of which may on occasions be so painful, distressing, and seemingly inescapable, they can lead to potentially tragic consequences.

To clarify further: anyone can experience a mental health difficulty; and everyone likely will at some stage of their lives. A mental health difficulty in most cases does not emanate from a physical illness or disorder. It is a common human challenge to be tackled creatively and constructively, including sometimes with the use of psychotherapy, and yes, medication, should that genuinely have something to contribute.

A Low Intensity Mental Health Difficulty interferes with a person's usual or preferred mental, emotional, and social capacity, and perhaps as well, their experience of feeling capable and competent.

Low intensity mental health difficulties are usually associated with major life changes and challenges, like: unemployment, sickness, loss and grief, money troubles, relationship difficulties, conflict, and stress. Low intensity mental health difficulties are common and are usually resolved through a person's own coping ability, adjustments to lifestyle, and the support of friends and family. Of course, professional help may also be important, particularly if a person becomes 'stuck' and can't seem to recover or move forward.

A High Intensity Mental Health Difficulty usually significantly impairs a person's ability to function on a day to day basis and noticeably interferes with their usual or preferred mental, emotional, or social capacity, and their experience of feeling capable and competent.

Such a difficulty, will usually require more than a person's own coping ability, lifestyle adjustments, and support of friends and family. At least initially, it will may require mapping and analysing by a qualified health professional (a doctor, psychotherapist, psychologist, or, in some cases a psychiatrist), who will also suggest and perhaps provide appropriate psychotherapy (psychological therapy).

In some cases, a General Medical Practitioner or Psychiatrist will also recommend prescription medication, which should be carefully considered for its potential to harm, evidence supporting its effectiveness (efficacy), and its appropriateness for the difficulty. If prescribed, it should be regularly reviewed both for any side-effects, and for whether it is genuinely helpful or still necessary.

\section{Mental Health Literacy}

Mental health literacy generally consists of several major components: recognition (symptom or illness recognition), knowledge (about sources of information, risk factors, causes, self-help and professional help), and attitudes (about mental illness, sufferers, and help-seeking). 2,3,4

The concept of mental health literacy is derivative of physical health literacy, the purpose of which is to increase patient knowledge about physical health, illnesses, and treatments. ${ }^{5}$

2. Jorm, A.F., Korten, A.E., Jacomb, P.A., Christensen, H., Rodgers, B. \& Pollitt, P. (1997). Mental health literacy: a survey of the public's ability to recognise mental disorders and their beliefs about the effectiveness of treatment. Medical Journal of Australia, 166, 182-186

3. Jorm, Anthony F. (2000). Mental health literacy: public knowledge and beliefs about mental disorders PDF. British Journal of Psychiatry.

4. O'Connor, Matt; Casey, Leanne; Clough, Bonnie (2014-08-01). Measuring mental health literacy - a review of scale-based measures. Journal of Mental Health. 23 (4): 197-204. doi:10.3109/09638237.2014.910646. ISSN 0963-8237.

5. Institute of Medicine (U.S.)., Hewitt, M., \& Maria Hewitt. (2012). Facilitating state health exchange communication through the use of health literate practices: workshop summary (Health Literate Practices) (1st ed.). National Academies Press. 


\section{Mental Health System}

Both government, and, government funded NGO services and agencies engaged in any form of mental health promotion, mental health literacy training, institutional or community based clinical mental health service delivery.

\section{Primary, Secondary, and Tertiary Prevention - relating to suicide prevention}

Primary prevention aims to prevent mental health difficulties and situational distress of a kind that are associated with suicide risk, from occurring. This approach may include community capacity building psycho-education, peer support training, lifestyle change training, but as well, addressing wider contextual socio-cultural, economic, political, and policy issues that impact on people's mental health and wellbeing.

Secondary prevention aims to reduce the impact of situational distress and mental health difficulties that have already occurred. This approach may include the provision of peer support, counselling and mental health support, identification of difficulties through GP screening, as well as selfidentification through community or other forms of education. Such early interventions try and 'nip problems in the bud' and either halt or as soon as possible resolve them.

Tertiary Prevention aims to soften the impact of an ongoing high intensity mental health difficulty, the ongoing risk subsequent to attempted suicide, and the ongoing impact of bereavement through suicide for those affected by a person who has died by suicide. Many current suicide prevention programs and initiatives are in the tertiary prevention category, which is a reflection of how suicide prevention has historically had its origins in and has been an element of activities within the mental health system, and has been conflated with mental illness.

*Adapted for this document from the RACGP Guidelines for the implementation of prevention in the general practice setting. ${ }^{57}$

\section{Situational Distress}

Situational distress encompasses a significantly challenging or troubling mixed experience of mind, thoughts, emotions, bodily sensations, or behaviours, associated with an apparent decompensating event, such as bereavement, a change in health status, relationship breakdown, financial, or occupational difficulties. This distress may significantly overlap with many of the symptoms usually taken to suggest mental 'illness' or 'disorder' (such as those associated with depression and anxiety). Even when distress is sometimes inexplicable, there is no good reason to automatically assume illness or disorder.

\section{Situational Approach to Mental Health Literacy}

A situational approach to mental health literacy, centres around the idea of situational distress which encompasses a significantly challenging or troubling mixed experience of mind, thoughts, emotions, bodily sensations, or behaviours, most often associated with an apparent challenging or decompensating life event, such as bereavement, a change in health status, relationship breakdown, financial, or occupational difficulties. This distress may significantly overlap with many of the symptoms usually taken to suggest mental 'illness' or 'disorder' (such as those associated with depression and anxiety). Even when distress is sometimes inexplicable, a situational approach discourages any presumption of illness or disorder.

The situational approach to mental health literacy is chiefly concerned with the broad spectrum of difficult and challenging life events and human experiences across the lifespan, and how these can be responded to in the most effective way to promote quality of life for individuals, as well as enhancing their capacity to meaningfully participate in and contribute to human community. This approach emphasises the importance of normalising human distress and encouraging constructive, effective, and non-pathologising responses to it. This will always mean seeing human experience in the context of gender 
specific considerations. Additionally, integral to this approach is an appreciation of contextual factors that potentially impinge on the mental health and wellbeing of individuals, families, and communities - factors that may need to be simultaneously addressed along with individuals' experience of distress.

The situational approach emphasises the vital importance of building community capacity for taking a primary role in promotion, prevention, and early intervention for mental health and suicide prevention, with mental health and other allied health professionals complementing these efforts. It also encourages lobbying and gaining the support of Government, corporate industry, and community leaders in addressing: needed improvement in social and mental health policy, and broader issues of contextual change to enhance mental health and wellbeing at the population level.

This approach does not downplay the importance of professional expertise in mental health, but proposes that this expertise be refocused, so that people with complex and very challenging mental health difficulties, are properly supported in environments and ways that focus on self-efficacy and recovery, without being unduly pathologised or diminished in dignity. However, at the same time, this approach proposes the activation of new sources of capacity - both community and professional, for promotion, prevention, and early intervention for mental health, and emphasises the importance of altering the balance of preventative mental health and suicide prevention with primary and secondary prevention being given primacy. ${ }^{57}$ 
NOTES 

